\title{
TÉCNICAS E SABERES IMBRICADOS NA ARTE DA PESCA DE CURRAL EM UMA RESERVA EXTRATIVISTA MARINHA DA AMAZÔNIA
}

\author{
Josinaldo Reis do NASCIMENTO ${ }^{1}$ \\ Eliza de Cássia Sousa DIAS ${ }^{2}$ \\ Terezinha de Jesus Lima de SOUZA² \\ Sergio Ricardo Pereira CARDOSO ${ }^{3}$ \\ Roberta Sá Leitão BARBOZA ${ }^{4}$
}

\begin{abstract}
RESUMO: Em Bragança (PA), nas comunidades litorâneas da RESEX Marinha Caeté-Taperaçu, conhecidas como vila dos Pescadores e vila do Bonifácio a pesca de curral é uma das principais atividades econômicas. Nesse sentido, a presente pesquisa investigou como os saberes-fazeres empregados na construção dos currais de pesca são repassados e valorizados ao longo do tempo. Para tal, foram aplicados formulários semiestruturados entre os pescadores de currais buscando compreender os saberes-fazeres usados na construção e implantação de currais de pesca, bem como as perspectivas destes curraleiros acerca desta atividade pesqueira. A iniciação na atividade ocorre ainda durante a infância, através dos pais. A socialização de saberes-fazeres de geração em geração através da vivência é característica básica dos saberes-fazeres tradicionais. A construção do curral de pesca é realizada em etapas, especialmente por pescadores peritos, contratados especificamente para este fim. O resultado mais preocupante observado está presente na própria fala dos pescadores sujeitos desta pesquisa, afirmando que a pesca de curral encontra-se em declínio em função da grande exploração de outras artes de pesca sobre os recursos pesqueiros do estuário, constatado pela diminuição da quantidade de peixes capturados no currais nos últimos anos.
\end{abstract}

PALAVRAS-CHAVE: Pesca artesanal, Saberes tradicionais, curral de pesca, RESEX Marinha Caeté-Taperaçu, Etnoecologia.

\begin{abstract}
In Bragança, in coastal communities RESEX marine Caeté-Taperaçu, called village of fishermen and village of Boniface, 'curral' fishing is one of the main economic activities for these localities. The research investigated the 'knowledge-doings' used in the construction of these trap fishing and how they are passed on and recovered over time. Semistructured questionnaires were applied among the fishermen trying to understand the "knowledge-doings" used in the construction and implementation of "currais" fishing, and the perceptions of these fishermen about these kind of fishery. Initiation in the activity still occurs during childhood with the parents. Socialization generation to generation of doings knowledge by experience is a basic characteristic of traditional knowledge. The construction of a "curral" fishing is made in stages, and only for expert fishermen, hired specifically for this purpose. The most worrying result observed is present in the very speech of the subjects fishermen of this research, stating that the corral fishing is in decline due to the large exploration of other fishing gear on fisheries of the estuary resources, evidenced by the decrease in amount of fish caught in corrals in recent years.
\end{abstract}

KEYWORDS: Artisanal fishing, Traditional knowledge, “curral” fishing, Caeté-Taperaçu marine RESEX, Ethnoecology.

\footnotetext{
${ }^{1}$ Mestre, Docente do Instituto Federal do Pará- IFPA Campus Bragança. Membro do Grupo de Pesquisa Educação, Trabalho, Tecnologia, Humanidades e Organização Social (ETTHOS). e-mail: josinaldo.reis@ifpa.edu.br

${ }^{2}$ Discentes do Curso Tecnólogo em Gestão Ambiental do Instituto Federal do Pará- IFPA Campus Bragança. E-mail: elizadias7@gmail.com e terezalima426@gmail.com

${ }^{3}$ Doutor, Docente do Instituto Federal do Pará- IFPA. Campus Bragança. Membro do Grupo de Pesquisa Educação, Trabalho, Tecnologia, Humanidades e Organização Social (ETTHOS). E-mail: sergio.pereira@ifpa.edu.br

${ }^{4}$ Doutora, Docente da Universidade Federal do Pará- UFPA Campus Bragança. Coordenadora do grupo de Pesquisa e Estudos Socioambientais Costeiros (ESAC). E-mail: robertasa@ufpa.br
} 


\section{INTRODUÇÃO}

A população da região nordeste do Pará, sobretudo a microrregião bragantina, apresenta o extrativismo como uma de suas principais fontes de renda. Nesta região a atividade extrativista é alicerçada no uso de recursos oferecidos pelos manguezais, pelas matas, pelos campos alagados e pelo ambiente marinho. O extrativismo pesqueiro se destaca por se configurar como uma das atividades mais importantes da zona costeira, sendo fonte de alimento, de trabalho e geradora de renda para parte significativa das populações humanas do litoral (SANTOS et al, 2005).

Existem várias modalidades de pesca, porém neste artigo será abordada a pesca ${ }^{5}$ artesanal, definida como uma categoria de pesca de "pequena escala", cujos apetrechos utilizados na captura dos recursos pesqueiros ${ }^{6}$ são considerados simples e baseados nos conhecimentos empíricos adquiridos e repassados ao longo da vida dos pescadores, como vários autores tem enfatizado (ESPÍRITO SANTO, 2002; ISAAC et al, 2008a; PIORSKI et al, 2009). A pesca artesanal destaca-se também por abranger vários apetrechos e técnicas na dinamização dos processos produtivos, por meio do emprego de um arcabouço de conhecimentos sobre o meio natural (estações do ano, safra das espécies alvo, oportunidades de captura), peculiar aos pescadores locais. Tais apetrechos e métodos muitas vezes são combinados entre si, afim de aumentar a capacidade de produção (ISAAC et al, 2008b).

Armadilhas constituem uma das diferentes técnicas utilizadas na pesca artesanal. Podem ser móveis ou fixas, funcionam atraindo o pescado para seu interior sem o uso de iscas e não impedem totalmente a sua saída. Suas denominações, bem como os materiais empregados na sua construção podem variar de acordo com o local de confecção. Verissimo (1895) já descrevia o uso de armadilhas fixas por pescadores do litoral do Pará desde o século 17.

Os currais de pesca constituem um tipo de armadilha fixa construído com cercas de madeira, geralmente extraídas do manguezal (Laguncularia racemosa e/ou Avicennia germinans), com entrada em forma de "V" que direciona os peixes para o seu interior, aprisionando-os. Estas armadilhas são encontradas em todo litoral brasileiro, principalmente na beira de praias, em bancos de areia onde há bastante influência dos regimes de marés (TAVARES et al, 2005; PIORSKI et al, 2009).

$\mathrm{Na}$ literatura existem controvérsias sobre seu surgimento, pois, alguns autores afirmam que os primeiros currais de pesca foram trazidos por imigrantes portugueses e instalados em praias do nordeste

\footnotetext{
${ }^{5}$ Pesca: toda operação, ação ou ato tendente a extrair, colher, apanhar, apreender ou capturar recursos pesqueiros (Lei $\mathrm{N}^{\circ}$ 11.959 de 29 de junho de 2009).

${ }^{6}$ Recursos Pesqueiros: são os animais e os vegetais hidróbios passíveis de exploração, estudo ou pesquisa pela pesca amadora, de subsistência, científica, comercial e pela aquicultura (Lei № 11.959 de 29 de junho de 2009).
} 
brasileiro, no entanto outros afirmam ser uma herança indígena aperfeiçoada ao longo do tempo por outros grupos de pescadores do litoral (FIDELLIS, 2013).

Controvérsias a parte, sabe-se que a ocorrências destas armadilhas de pesca no litoral brasileiros dependem da transmissão dos saberes-fazeres entre as gerações. Neste sentido, o presente artigo investigou in locu como as técnicas e saberes empregados na construção dos currais de pesca são repassados e valorizados pelos pescadores na Vila dos Pescadores e Vila Bonifácio, Ajuruteua. Para tal, buscou-se responder aos seguintes questionamentos: Como esses saberes são repassados? Que tipos de currais existem na região? Quais saberes imbricados na construção de um curral de pesca?

\section{MATEIRAIS E MÉTODOS}

\section{Área de Estudo}

A área de estudo localiza-se na Planície Costeira Bragantina, situada no estuário do rio Caeté, município de Bragança, e abrange desde a Ponta do Maiaú até a foz do Caeté, constituindo cerca de 40 $\mathrm{km}$ de extensão entre os paralelos $00^{\circ} 43^{\prime} \mathrm{S}$ e $00^{\circ} 04^{\prime} \mathrm{S}$ e os meridianos de $46^{\circ} 32^{\prime} 16^{\prime}$ ' $\mathrm{W}$ e $46^{\circ} 55^{\prime} 11^{\prime}$ ' $\mathrm{W}$ (CAMARGO \& ISAAC, 1998; SOUZA-FILHO, 2001) (Figura 01).

A vila dos Pescadores surgiu entre os anos de 1913 e 1915 com a chegada de imigrantes cearenses (Maneschy, 1995). As casas são de madeira construídas sobre campos de dunas próximo a um canal de maré. À medida que o canal avança as casas são desmontadas e transferidas para locais mais altos se aproximando da vila do Bonifácio (CARNEIRO et al. 2010).

A vila dos Pescadores e a vila do Bonifácio estão localizadas a $36 \mathrm{~km}$ da sede do munícipio de Bragança, e estão inseridas na Reserva Extrativista Marinha Caeté-Taperaçú que possui área de 42.068,086 ha (quarenta e dois mil e sessenta e oito hectares, oitenta e seis ares) (BRASIL, 2005). 


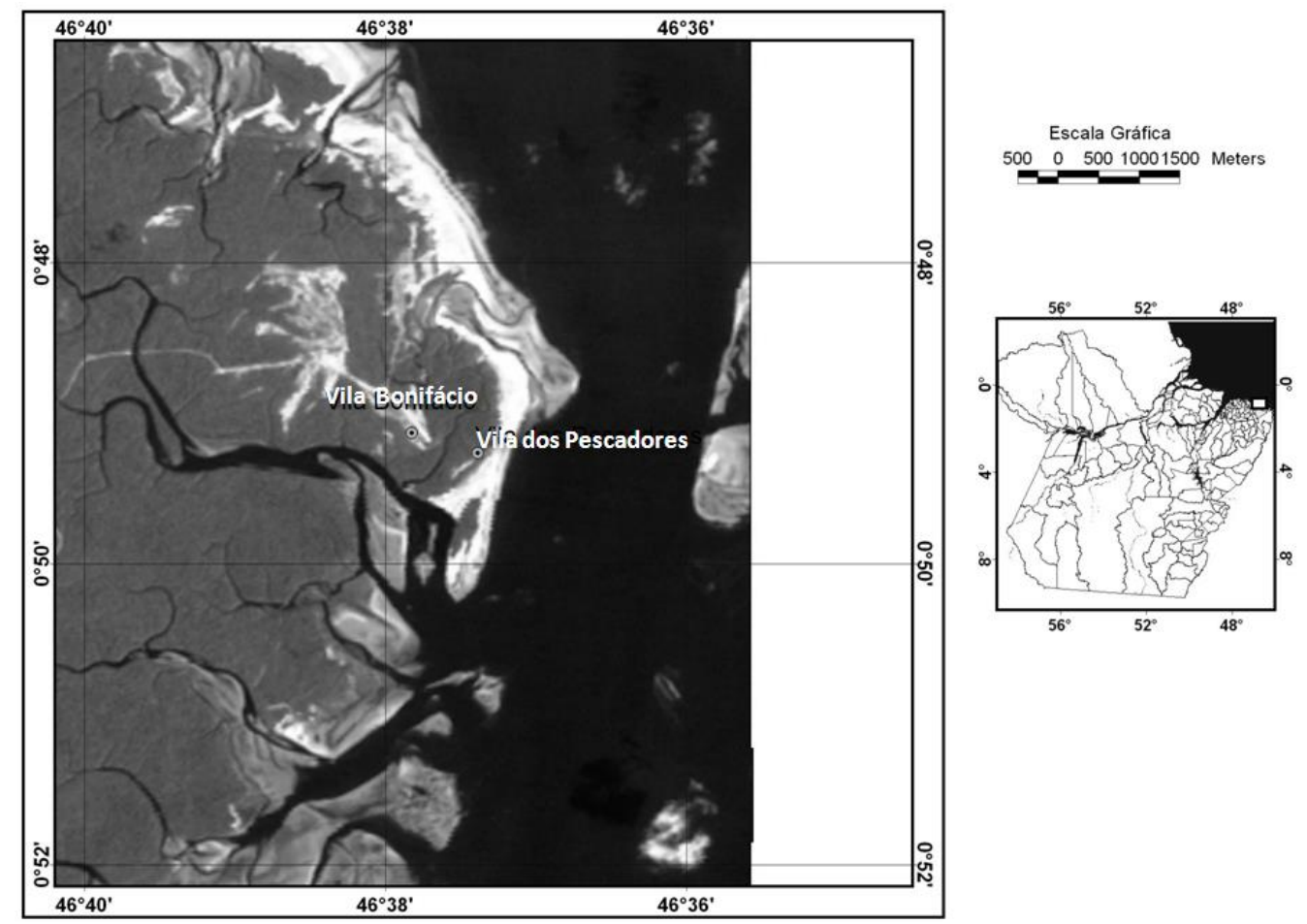

Fig. 01- Localização da área de estudo, destacando as vilas dos Pescadores e Bonifácio (Fonte: Barboza et al., 2011).

\section{Procedimentos Metodológicos}

A profunda crise ecológica gerada pelos atuais modelos produtivos rurais (agropecuários, florestais, pesqueiros e extrativistas), cujas consequências são fenômenos tais como a depredação da terra e dos recursos hidráulicos, a deflorestação, a salinização, a extinção da flora e da fauna e as mudanças meteorológicas e climáticas locais, regionais, nacionais e globais, estão induzindo mudanças na maneira de enxergar as problemáticas e conceber as investigações científicas, causando o aparecimento de novos paradigmas metodológicos e teóricos.

Dentro desse contexto, destaca-se uma nova forma de abordar os fenômenos, no sentido de (re)valorizar os saberes-fazeres tradicionais sobre o uso da natureza e resgatar para este cenário o protagonismo das comunidades rurais na superação da crise ecológica. Esta nova maneira de fazer ciência se chama etnoecologia, que, num sentido mais amplo, esforça-se por retomar as práticas tradicionais de manejo dos recursos naturais como ponto de partida para se desenhar posturas alternativas de produção que sejam ecologicamente viáveis (POSEY, 1984; TOLEDO, 1992).

Baseado, então, nos preceitos da etnoecologia, estabeleceram-se algumas estratégias e procedimentos metodológicos, que serão descritos de forma mais detalhada nas linhas a seguir.

Durante o período de maio/2014 a agosto/2015 foram realizadas entrevistas semiestruturadas (VIERTLER, 2002), utilizando um formulário direcionado aos pescadores donos de curral da vila dos Pescadores e vila Bonifácio na praia de Ajuruteua. 
Optou-se pela postura de "ouvinte-aprendiz", o que não significa dizer que o pesquisador se tornou totalmente passivo; pretendeu-se dar respostas (afinal, para que serve a pesquisa?), mas tão somente baseadas em dados presentes num contexto local, sem conclusões precipitadas nem receitas prontas.

Optou-se pela entrevista semiestruturada, pois esta permite uma maior fluência e liberdade para expor opiniões e informações por parte do entrevistado (VIERTLER, 2002). Pela questão da falta do domínio da escrita por uma grande parte dos pescadores, privilegiou-se as entrevistas de forma oral, mas, dependendo da sensibilidade do entrevistador ou mesmo das escolhas dos entrevistados, fez-se mudanças para o registro escrito. Além das entrevistas, realizaram-se registros fotográficos, principalmente nas observações sobre os fazeres propriamente dito.

Adotou-se a amostragem do tipo "snow ball” (Bailey, 1994 apud Albuquerque \& Lucena, 2004), que consiste na indicação dos novos informantes pelos próprios entrevistados. Como estratégia de verificar a veracidade das informações, segundo Johannes (1981), foram realizadas, também, entrevistas sincrônicas (mesma entrevista com diferentes entrevistados simultaneamente) e entrevistas diacrônicas (repetições das perguntas ao mesmo entrevistado, após um considerado intervalo de tempo).

Os formulários utilizados continham perguntas acerca da participação dos curraleiros em organizações coletivas, do tempo de atuação na atividade, das técnicas de construção de currais e de suas perspectivas acerca deste tipo de pesca.

A explanação e análise dos dados obtidos constituíram-se de caráter misto, ou seja, quantitativo e qualitativo, sendo que este cumpriu, segundo Moraes (1999), 4 etapas distintas: Unitarização, que se resume na transcrição e leitura das entrevistas com o objetivo de captar as unidades de análise, que são pistas-chaves de conteúdo, que ajudarão na construção das categorias de análise; Categorização, que consiste na reunião dos dados por afinidade ou semelhança com o objetivo de formar categorias temáticas; Descrição, que se trata da explanação dos resultados encontrados na pesquisa de campo; Interpretação, que seria a reflexão e compreensão dos dados descritos por meio do confronto com o conhecimento científico.

\section{RESULTADOS E DISCUSSÃO}

Um total de dez pescadores proprietários de currais de pesca foram identificados na área de estudo, no entanto a amostragem deste estudo correspondeu a 9 curraleiros entrevistados. Todos os curraleiros são do sexo masculino distribuídos em uma faixa etária que variou entre 28 e 63 anos, com média de idade de 51,6 anos. Apresentaram uma média de 27,5 anos de trabalho apenas na pesca de curral, sendo que $62,5 \%$ dos entrevistados possuem mais de um curral de pesca. 
Verificou-se que a grande parte dos curraleiros entrevistados (75 \%) são membros da Colônia dos Pescadores do município de Bragança (Z-17). De acordo com os entrevistados é importante a participação na organização, principalmente como garantia de acesso aos benefícios de seguridade social, como a aposentadoria.

Além de membros da Colônia de pescadores, participam da Associação dos Usuários da Reserva Extrativista Marinha Caeté-Taperaçu (ASSUREMACATA) que engloba uma grande parte dos pescadores de todo território da RESEX marinha. Segundo eles a ASSUREMACATA apresenta a tarefa de mantê-los informados sobre a legislação pesqueira, seus direitos e deveres como pescadores da RESEX. Quando questionados sobre a RESEX, todos informaram já ter ouvido falar na RESEX Marinha Caeté-Taperaçu, enquanto 75\% afirmaram que a RESEX trouxe algum benefício para seus usuários, através da construção de casas e apoio junto ao INCRA (Instituto Nacional de Colonização e Reforma Agrária) na obtenção de créditos para aquisição de utensílios e materiais de trabalho. Os curraleiros afirmaram ainda que durante as reuniões da ASSUREMACATA são discutidos aspectos da legislação pesqueira, desse modo, buscam se adequar às normas vigentes para evitar conflitos com os órgão gestores.

De acordo com Barroso \& Fabiano (1995) os pescadores artesanais organizam-se em colônia de pescadores, normalmente, em busca de garantias de seguridade social, assistência médica e dentária. No entanto, a pesquisa de Fidellis (2013) apontou que no município de São Caetano de Odivelas, nordeste do Pará, 55 \% dos pescadores não são membros da Colônia de pescadores ou outra organização, esta falta de interesse ou motivação pode refletir em maiores dificuldades enfrentadas por estes trabalhadores, sobretudo no que tange a seguridade social.

Os curraleiros de Ajuruteua afirmaram que a escolha do tipo de curral depende do local onde o mesmo será instalado e dos custos financeiros necessários à sua construção.

Em termos estruturais as partes essenciais de um curral de pesca são: (a) espia (estrutura tipo uma cerca que intercepta os peixes e os dirige para outros compartimentos da armadilha); (b) sala (local por onde os peixes passam após percorrerem toda a espia) e (c) depósito (estrutura final da armadilha, local onde os peixes ficam aprisionados definitivamente e os pescadores podem proceder com a despesca) (MANESCHY, 1993) (Figura 02).

Os currais de pesca, recebem nomenclaturas variadas dependendo da região (MANESCHY, 1993; ROSA, 2007; PIORSKI, 2009; FIDELLIS, 2013). Atualmente são encontrados quatro principais tipos de currais de pesca ao longo do litoral paraense:

Curral em Coração - Possui uma espia, uma sala e um depósito. Segundo Maneschy (1993) deve ser construído "atravessado" em relação as correntes de maré para capturar os peixes tanto de maré enchente, quanto de maré vazante. 
Curral em Cachimbo - Este tipo de curral de pesca possui espia, sala e depósito, porém, diferencia-se do tipo coração devido à disposição do depósito: está localizado na lateral da sala.

Curral de Enfia - Este tipo de armadilha fixa possui uma ou duas espias e depósito. Este tipo de curral captura peixes apenas durante a maré vazante, logo, possui espias bem longas, com cerca de 50 a 80 metros de comprimento.

Curral de Enfia-Coração - Este tipo de armadilha é uma evolução das versões citadas anteriores, uma união entre os tipos coração e enfia. Estruturalmente possui espia, salão, sala e depósito. Este tipo "misto" de curral, captura peixes tanto de maré enchente, quanto de maré vazante, por isso é considerado pelos pescadores como o tipo de curral mais produtivo e eficiente, no entanto o grau de complexidade na confecção é bem maior, por exigir grandes espaços, destrezas do construtor e maior nível de investimentos.

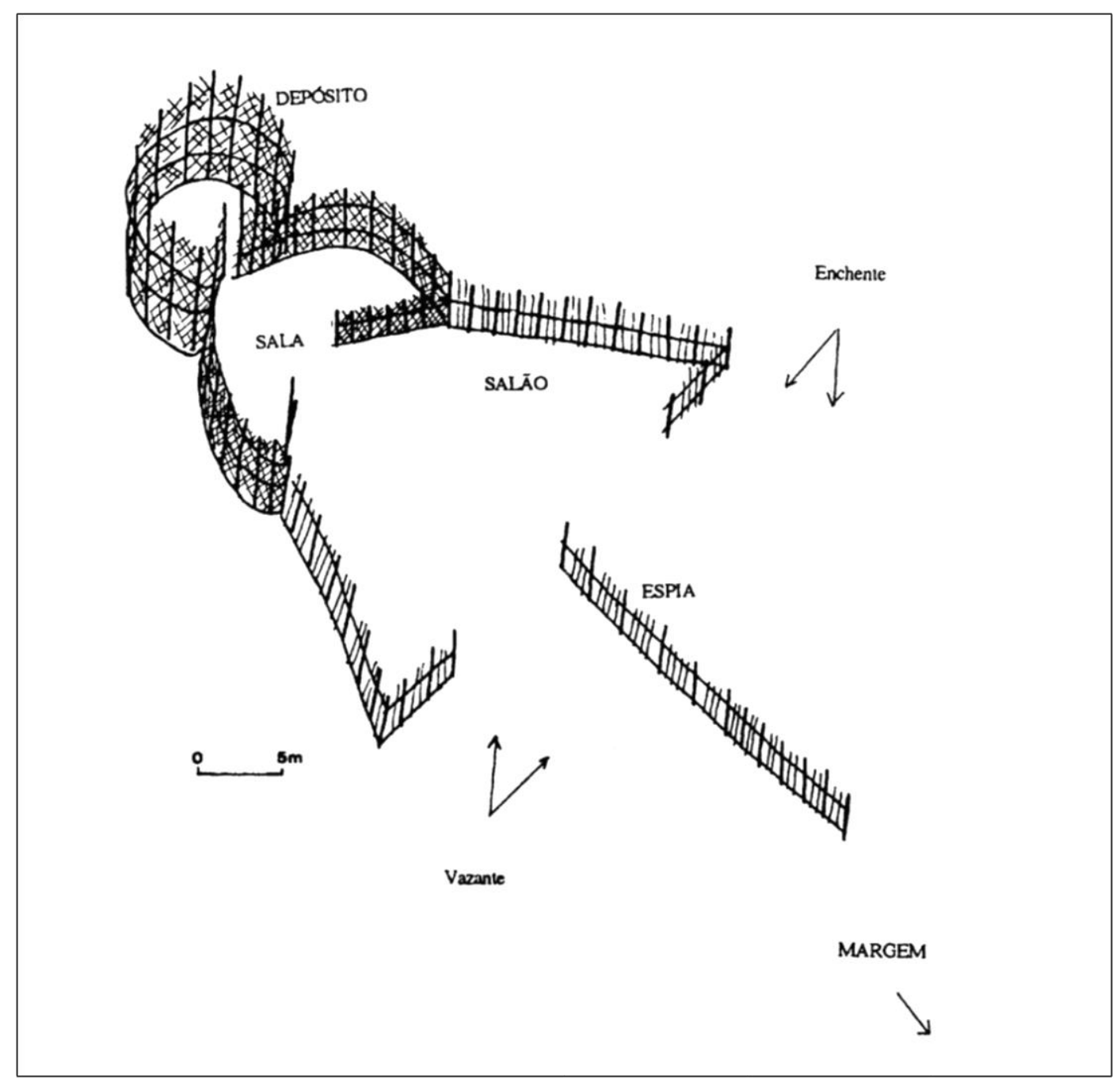

Fig.1- Desenho esquemático de um curral de pesca do tipo Enfia-Coração, mostrando suas compartimentalizações (Fonte: Maneschy, 1993). 
$\mathrm{Na}$ área de estudo registrou-se um total de 16 currais de pesca ativos, caracterizados como do tipo "enfia".

Os curraleiros justificaram a utilização deste tipo de curral por considerarem-no o mais tradicional e apropriado para a região: captura maiores quantidades de pescado e apresenta melhor custobenefício, por usar menor quantidade de redes e ser mais resistente, embora os outros materiais sejam considerados caros (Figura 03).

Segundo Maneschy (1993) e Fidellis (2013) em São Caetano de Odivelas são encontrados principalmente 3 tipos de currais de pesca: coração, enfia e enfia-coração, sendo o curral coração mais comum. Por outro lado, em Marudá, município de Marapanim, Furtado em 1980 descreveu a presença sobretudo de currais tipo enfia-coração.

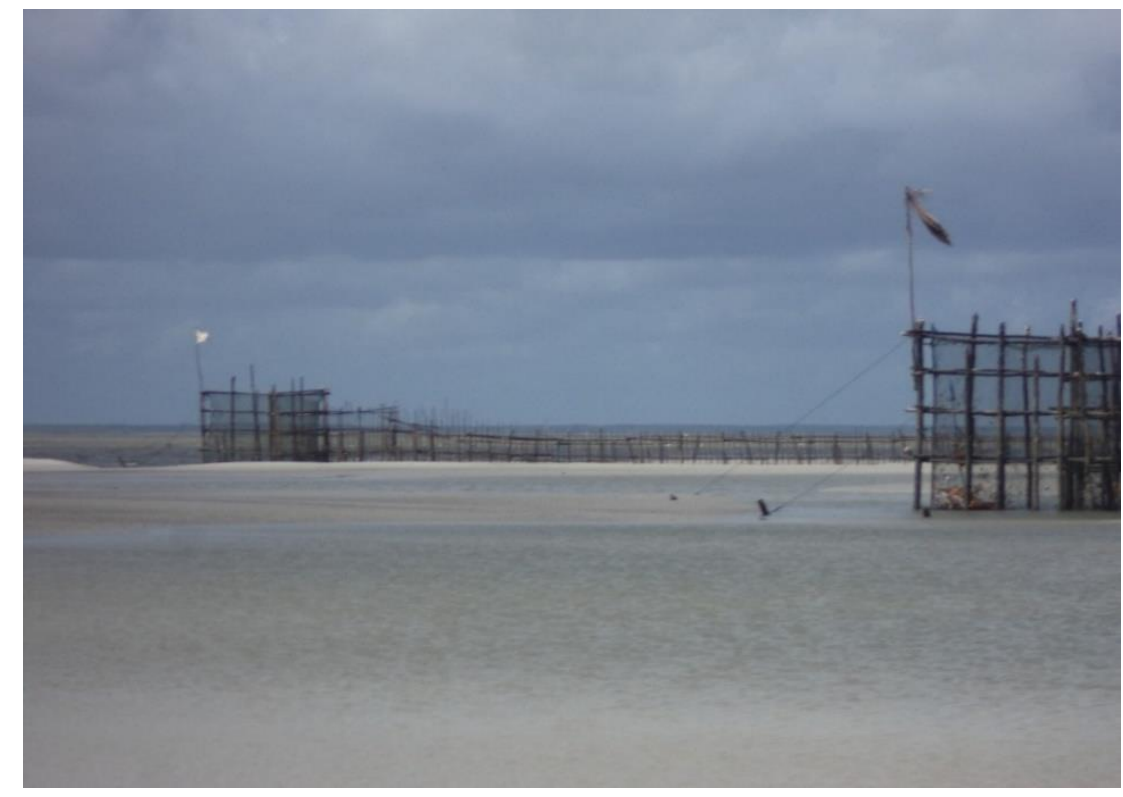

Fig. 03- Vista lateral de um Curral do tipo Enfia nas proximidades da Vila dos Pescadores em Ajuruteua, Bragança-PA (Fonte: Eliza Dias, 2015).

A construção de um curral de pesca é realizada em diferentes etapas por pescadores experientes, considerados localmente como peritos na arte de construir estas armadilhas.

A primeira etapa constitui a seleção do local e marcação do curral. Conforme descreve Fidellis (2013) vários fatores influenciam a escolha da área onde o curral de pesca será construído, destacandose a tradição familiar, a dinâmica do ambiente, a distância de áreas habitadas a fim de evitar sua destruição, e principalmente em função da produtividade pesqueira. De acordo com os pescadores de Ajuruteua, a escolha do local é realizada, sobretudo, levando em consideração a direção das correntes de marés, pois é importante que estas passem por croas antigas as quais são bons pontos de pesca e garantem uma boa produtividade aos currais. 
A marcação determinará se o curral construído capturará “de enchente” ou "de vazante”. Consiste em estabelecer a posição que o curral ficará em relação as correntes de maré. Esta etapa da confecção do petrecho requer desenvoltura, competência e experiência, sendo avaliada por muitos pescadores como a etapa mais delicada da construção. Geralmente é desenvolvida por um pescador experiente que tenha grande conhecimento sobre marés, ventos e a dinâmica da região para marcar os principais pontos de construção.

Piorski (2009) também destaca que os saberes acerca da marcação de um curral de pesca consistem em um trabalho minucioso, o qual requer experiência e destreza do pescador. Em Ajuruteua, marcadores são contratados especificamente para este fim, confirmando os achados de Piorski (2009), embora $16 \%$ dos curraleiros também façam a sua própria marcação.

A segunda etapa refere-se à escolha e retirada de madeira para ser utilizada na construção. Parece haver certa preocupação com as áreas selecionadas para realizar o corte de madeiras com alternância dessas áreas a fim de possibilitar a regeneração das arvores nestas áreas. As madeiras usadas são oriundas das florestas de mangue adjacentes as vilas: tinteiro (Laguncularia racemosa), siribeira ou siriúba (Avicennia germinans) e o mangueiro (Rhyzophora mangle) (SAINT-PAUL, 2006; CARNEIRO et al., 2010). A escolha da madeira é realizada de acordo com sua funcionalidade no curral: troncos mais grossos destinam-se aos moirões e troncos mais finos ao cintado e ao paris (Figura 04). $\mathrm{O}$ transporte das madeiras ocorre em canoas motorizadas (rabetas) percorrendo os furos que cortam os mangues adjacentes às vilas.

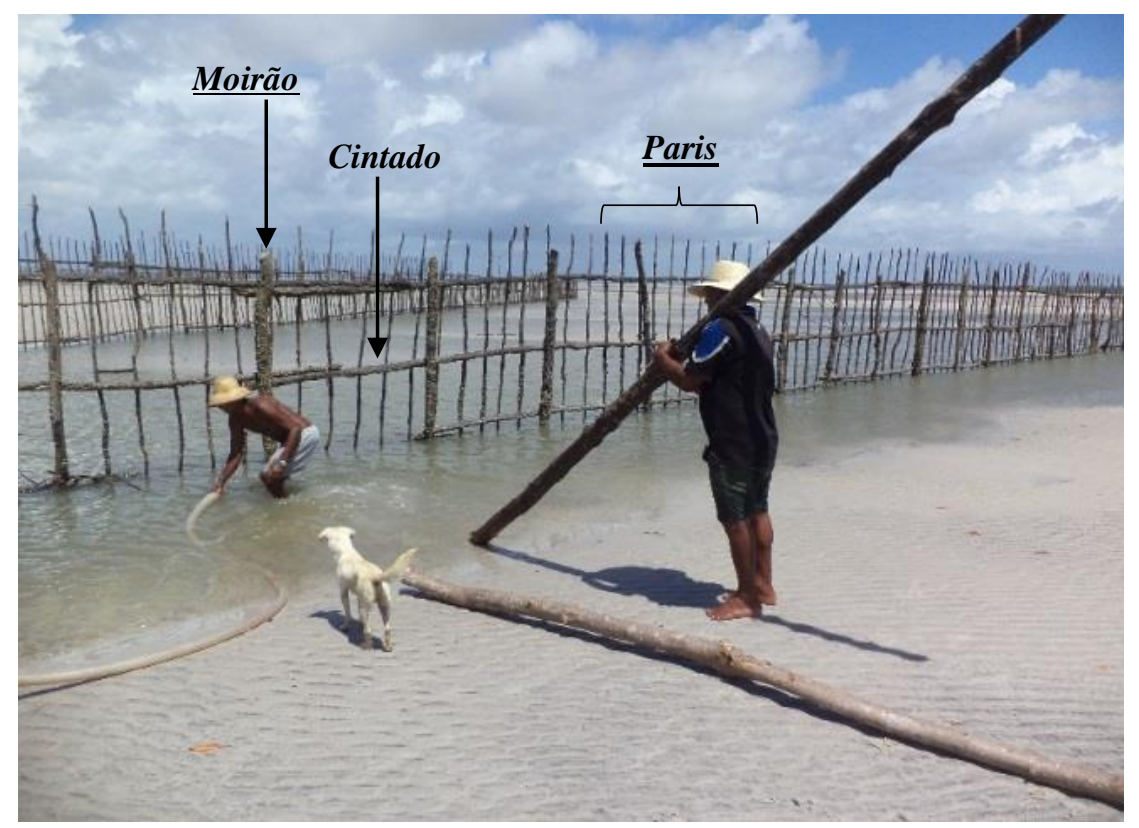

Fig. 4- Curral de pesca com destaque para os moirões, paris e cintados (Fonte: Eliza Dias, 2015). 
Quando a madeira já foi coletada e transportada, e a área escolhida já foi demarcada, inicia-se a última etapa da construção do curral: a fixação das estruturas da armadilha. Inicialmente são instalados os moirões do depósito, em seguida os pescadores iniciam a construção das espias (estruturas semelhantes a uma cerca, construídas com varas de madeiras mais finas que possuem em média 6 a 10 centímetros de diâmetro, podendo chegar a mais de 3,5 metros de altura, dependendo da amplitude da maré no local). A distância entre as varas não ultrapassa 3 centímetros. Também devem ser colocados os paris para unir os moirões. Por fim, na posição horizontal é fixado o cintado, estrutura que garantirá a segurança do curral de pesca.

O primeiro compartimento construído é o chiqueiro, compartimento do curral onde os peixes capturados ficam aprisionados até a despesca. Em outros municípios como Curuçá, São Caetano de Odivelas, os pescadores denominam este compartimento de depósito (Figura 02), (MANESCHY, 1993). Nesta estrutura são enfiados os moirões verticalmente com distância de até duas braças entre cada moirão. Este trabalho é realizado com o auxílio de um motor a gasolina, formado por duas mangueiras acopladas: uma mangueira suga água e a outra jorra a água com força suficiente para abrir um buraco onde o moirão será fixado ao chão (5 a 7 metros de altura e diâmetro de cerca de $20 \mathrm{~cm}$ ) (Figura 05). Nos estudos de Piorski (2009) é citada a utilização de "dragas" e "alavancas" em São Luis como ferramentas para construção, enquanto Maneschy (1993) já descrevia em 1990 o uso de motores em São Caetano Odivelas.

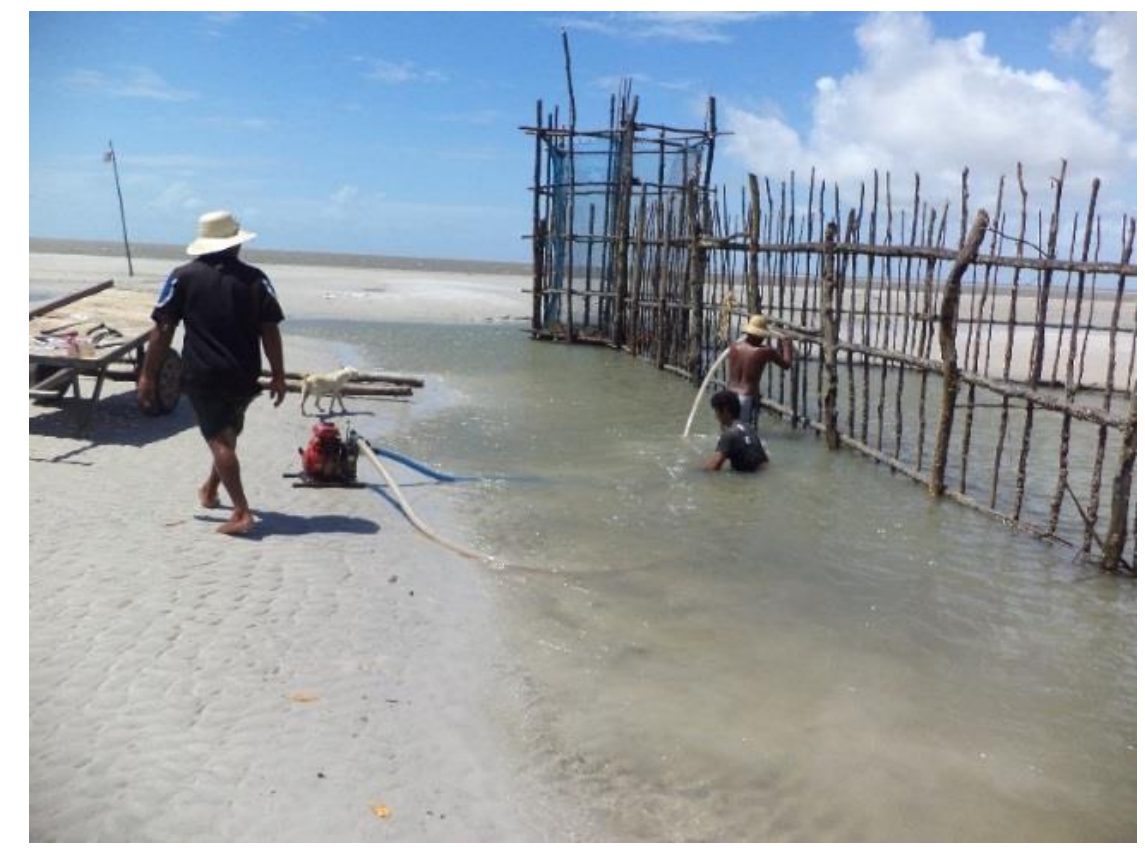

Fig. 5. Implantação dos moirões de um curral de pesca com auxílio do motor a gasolina (Fonte: Eliza Dias, 2015). 
Os currais encontrados em Ajuruteua apresentaram aproximadamente 150 moirões em sua estrutura. Os chiqueiros possuíam cerca de 5,5 braças, equivalendo a aproximadamente 9 metros, e as espias variaram entre 50 e 75 braças de comprimento, sendo que uma braça possui cerca de 1,65 metros, totalizando uma média de 112 metros de comprimento. Além da madeira também são utilizadas redes de pesca sintéticas, cordas sintéticas e pregos na confecção de um curral. O tamanho da malha das redes encontradas nos chiqueiros foi de $25 \mathrm{~mm}$ entre nós opostos. Vale ressaltar que o recomendando pelo plano de manejo da Resex Marinha Caeta-Taeparcu é de $40 \mathrm{~mm}$ entre nós opostos (ABDALA, et al 2012). No entanto, durante as pesquisas in locu verificou-se que no momento das despescas, esses peixes muito pequenos são separados e devolvidos ao mar, pois de acordo com os próprios curraleiros "é melhor deixar que eles cresçam e reproduzam, porque dessa forma futuramente ainda terão produção pesqueira."

Piorski (2009) constatou que em São Luís (Maranhão) os currais de pesca possuem espias com média de 9 metros de comprimento e os chiqueiros possuem cerca de 5 metros de largura. Estes são confeccionados com dois tipos de redes; na parte superior são usadas redes com 50 mm entre nós opostos e na parte inferior redes com $30 \mathrm{~mm}$ entre nó opostos, demonstrando que a distância entre nós opostos encontrados nos currais do Maranhão para aquele período de estudo eram maiores que a distância dos nós opostos dos currais atualmente construídos em Ajuruteua.

Nos currais do tipo enfia observados nas proximidades da vila dos Pescadores, tanto os localizados na desembocadura do estuário, quando os instalados em bancos de areia na praia, verificouse a presença de uma estrutura no interior do chiqueiro, projetada para facilitar a despesca e a locomoção dos pescadores, conhecida como "piso". Este piso é confeccionado com a mesma madeira utilizada no cintado. Esta estrutura geralmente é construída junto a lâmina d'agua da maré vazante, pois assim evita que os peixes morram antes da despesca.

Todos os proprietários de currais de pesca que compuseram esta pesquisa afirmaram reformar seus currais periodicamente e realizar inspeções e limpezas a cada despesca, pois pode haver algum moirão danificado por caracas $^{7}$ fixadas na madeira e/ou lixo trazido pelas marés. Os períodos de reforma variam de acordo com os danos provocados pelas correntes de marés, sendo realizados em geral a cada 3 meses, em função do desgaste dos materiais, os quais necessitam serem trocados durante o período de mudança de safra ${ }^{8}$.

\footnotetext{
${ }^{7}$ É o nome comum para um tipo de crustáceo marinho, séssil da ordem Thoracica, classe Cirripedia. Estes animais quando adultos possuem um exoesqueleto calcificado composto por várias placas que definem uma forma cónica (OLIVEIRA, 1941). As cracas ou caracas fixam-se normalmente em substratos rochosos, mas podem fixar-se também ao fundos de embarcações, em pontes de madeiras em zonas estuarinas onde causam grandes estragos.

${ }^{8}$ Os curraleiros apontaram o período compreendido entre abril e julho como mais produtivo na região, em virtude da safra da principal espécie alvo desta modalidade de pescaria: a pescada gó (Macrodon ancylodon) (CAMARGO \& ISAAC, 1998; 2005; BARBOZA et al., 2011).
} 
A manutenção dos currais em São Caetano de Odivelas inclui inspecionar as amarras, raspar as caracas com facão, examinar o rodapé do depósito e atulhar ${ }^{9}$ possíveis buracos nas redes (FIDELLIS, 2013).

Os curraleiros demonstraram expectativa negativa em relação ao futuro da atividade em função de práticas de pesca predatórias realizadas próximo a linha de costa, como a pesca de arrasto que pode estar contribuindo para o declínio da produção dos

currais atualmente.

Verificou-se na área estudada um certo declínio da atividade pesqueira, de modo geral os mais jovens têm buscado outras oportunidades fora da pesca, principalmente quando os recursos pesqueiros encontram-se muito explorados. Os curraleiros indicaram a importância de implementação de uma legislação especifica para o ordenamento efetivo desta modalidade de pesca, com vistas a reprodução dos seus meio de vida.

\section{CONCLUSÕES}

De acordo com a região e as necessidades do pescador, os currais podem variar de formas e denominações, com o intuito de facilitar o trabalho do pescador. Os currais de pesca registrados nas proximidades da Vila dos pescadores são todos do tipo Enfia.

A construção desse tipo de armadilha exige conhecimento detalhado (direção das correntes, maré, espécies arbóreas, deslocamento dos peixes, geometria, entre outros) e grande habilidade, que não são comuns a todos. Há inclusive a figura do perito em currais, pessoa com reconhecida experiência na arte de construção desta arte pesqueira. A técnica de pesca de curral é passada de geração para geração através do conhecimento empírico adquirido com as experiências vividas, em geral são filhos que acompanham os pais na atividade. Todavia, esta arte encontra-se em declínio em Ajuruteua, os mais jovens têm buscado outras oportunidades e muitos acabam não seguindo a profissão dos pais, principalmente quando os recursos pesqueiros encontram-se sobrexplorados.

Observaram-se alguns aspectos 'conservacionistas' entre os pescadores, na medida em que escolhem as áreas de corte da madeira e devolvem ao ambiente marinho-estuarino peixes pequenos capturados pelos currais, por outro lado, os mesmos têm utilizado pequenas malhas em sua estrutura. Estudos mais aprofundados sobre essa temática devem ser realizados para compreender melhor a relação dos pescadores curralistas com questões conservacionistas.

\footnotetext{
${ }^{9} \mathrm{O}$ "atulhamento" de currais consiste em colocar galhos e ramos de árvores na base das estacas dos currais, para que estes galhos impeçam que a maré carreie os sedimentos e forme um poço profundo dentro do curral (CARNEIRO, et al., 2010, p. 1031)
} 


\section{REFERÊNCIAS}

ABDALA, Guilherme; SARAIVA, Nicholas; WESLEY, Fábio. Plano de Manejo da Reserva Extrativista Marinha de Caeté-Taperaçu - Volume II - Planejamento das Unidades. Brasília: ICMBio. 162 p., 2012.

ALBUQUERQUE, Ulysses Paulino; LUCENA, Reinaldo Farias Paiva. Métodos e técnicas para coleta de dados. In: ALBUQUERQUE, Ulysses Paulino; LUCENA, Reinaldo Farias Paiva \& CUNHA, Luiz Vital F. Cruz da Cunha. (orgs), Métodos e Técnicas na Pesquisa Etnobotânica. Editora Livro Rápido/NUPEEA, Recife, p. 37-62. 2004.

BARBOZA, Roberta Sá Leitão; PEZZUTI, Juarez Carlos Brito. Etnoictiologia dos pescadores artesanais da Resex Marinha Caeté-Taperaçu, Pará: aspectos relacionados com etologia, usos de hábitat e migração de peixes da família Sciaenidae. Sitientibus série Ciências Biológicas 11(2): 133 141. 2011.

BARroso, Lisia Vanacôr; FABIANO, Fabio F.C. Estudo da Pesca com Arte Fixa na Lagoa de Araruama (RJ). Programa de Pós Graduação em Ecologia- Instituto de Biologia- UFRJ. Rio de Janeiro, Oecologia Brasiliensis, v. 1, p. 569-585, 1995.

CAMARGO, Mauricio; ISAAC, Victoria Judith. 1998. Populations structure of fish fauna in the estuarine area of Caeté River, Pará, Brazil. Acta Scientiarum 20(2): 171-177.

BRASIL. Diário Oficial da União- Seção 1. Distrito Federal DF, 23 de maio de 2005.

BRASIL. Diário Oficial da União- Seção 1. Lei n. 11959, de 29 de junho de 2009. Casa Civil, Subchefia para Assuntos jurídicos. Brasília, 2009.

CAMARGO, Mauricio; ISAAC, Victoria Judith. Population structure of fish fauna in the estuarine area of Caeté River, Bragança, Pará, Brazil. Acta Scientiarum, v. 20, n. 2, p. 171-177, 1998.

CARNEIRO, Diogo Borges; BARBOSA, Myrian Sá Leitão; MENEZES, Moirah Paula. Plantas Nativas Úteis na Vila dos Pescadores da Reserva Extrativista Marinha Caeté Taperaçu, Pará, Brasil. Acta Botânica Brasílica, 2010.

ESPÍRITO SANTO, Roberto Vilhena do. UFPA. Caracterização da Atividade de Desembarque da Frota Artesanal de Pequena Escala na Região Estuarina do Rio Caeté, Município de Bragança Pará - Brasil., dissertação de mestrado. 2002.

FIDELLIS, Carolina de Nazaré Aleixo. A Pesca de Curral no Município de São Caetano de OdivelasPA. Programa de Pós Graduação em Ecologia Aquática e Pesca- UFPA. Belém, 2013.

ISAAC, Victoria Judith; ESPÍRITO SANTO, Roberto Vilhena do; ALMEIDA, Morgana Carvalho de; ALMEIDA, Oriana; ROMAN, Ana Paula; NUNES, Leocyvan. Diagnóstico da Pesca e da Aquicultura 
do Estado do Pará. Diagnóstico, Tendência, Potencial e Política Pública para o Desenvolvimento do Setor Pesqueiro Artesanal. Belém, v. 2, 2008a

ISAAC, Victoria Judith; ESPÍRITO SANTO, Roberto Vilhena do; NUNES, José L. G. A Estatística Pesqueira no Litoral do Pará: Resultados Divergentes. Pan-American Journal of Aquatic Sciencis, p. 205-213, 2008b.

JOHANNES, Robert E. Working with fishermen to improve coastal tropical fisheries and resource management. Bulletin of Marine Science, v. 31, n. 3, p. 673-680, 1981.

MANESCHY, Maria Cristina. Pescadores Curraleiros no Litoral do Estado do Pará: Evolução e Continuidade de uma Pesca Tradicional. Revista da SBHC, n. 10, p. 53-74, 1993.

MANESCHY, Maria Cristina. In: Ajuruteua, uma Comunidade Pesqueira Ameaçada. Belém, Ed. Universitária UFPA. 1995.

MORAES, Roque. Análise de conteúdo. In: Educação XXII (37), 1999, p. 7-32.

PIORSKI, Nivaldo Magalhães; SERPA, Sheila Silva e; NUNES, Jorge Luiz Silva. Análise Comparativa da Pesca de Curral na Ilha de São Luís, Estado do Maranhão, Brasil. Arquivos de Ciências do Mar, Fortaleza, 2009.

POSEY, Darrell. A. et al. Ethnoecology as applied anthropology in Amazonian development. In: Human Organization, $\mathrm{n}^{\circ}$ 43, p. 95-107, 1984.

ROSA, Benilde de Nazaré Lameira. Somos Parceiros?: Representações e Relações Sociais na Pesca em Unidades de Conservação-Em foco a APA da Costa de Urumajó. Programa de Pós Graduação em Ciências Sociai, Instituto de Filosofia e Ciências Humanas- UFPA, Belém, 2007.

SAINT-PAUL, Ulrich. Interrelations among Mangroves, the Local Economy and Social Sustainability: Review from. Environment and Livelihoods in Tropical Coastal Zones, p. 154, 2006.

SANTOS, Marcos Antônio Souza dos; GUERREIRO FILHO, Mário Corino Siqueira; NEVES, Paulo Rogerio dos Santos; AGUIAR, Cláudia Glaucilene Guimarães de. Análise Socioeconômica da Pesca Artesanal no Nordeste Paraense. XLIII Congresso da Sober, Ribeirão Preto, 2005.

SOUZA-FILHO, Pedro Walfir Martins. Impactos naturais e antrópicos na Planície Costeira de Bragança. In: Ecossistemas Costeiros: Impactos e Gestão Ambiental, Ed. Belém: MPEG, p. 113-125, 2001.

TAVARES, Márcia Cristina da Silva; FURTADO JÚNIOR, Ivan; SOUZA, Raimundo Anderson Lobão de; BRITO, Carla Suzy Freire. A Pesca de Curral no Estado do Pará. Boletim Técnico Científico CEPNOR. Belém, v. 5, n. 1, p. 115-139, 2005.

TOLEDO, Victor. M. What is Ethnoecology? Origins, scope and implications of a rising discipline. In: Etnoecológica 1 (1), p. 05-21, 1992.

VERÍSSIMO, José. A pesca na Amazônia. Livraria clássica de Alves. Rio de Janeiro, 1895. 
VIERTLER, Renate Brigitte. Métodos antropológicos como ferramenta para estudos em etnobiologia e etnoecologia. In: AMOROZO, M. C. M.; MING, L. C.; SILVA, S. M. P. (Ed.). Métodos de coleta e análise de dados em etnobiologia, etnoecologia e disciplinas correlatas. Rio Claro: UNESP/ CNPq. p.11-29, 2002. 